\title{
OPTIMIZATION IN DAY-AHEAD PLANNING OF ENERGY TRADING
}

\author{
Minja Marinović* \\ Faculty of Organizational Sciences, Belgrade, Serbia \\ Dragana Makajić - Nikolić \\ Faculty of Organizational Sciences, Belgrade, Serbia \\ Milan Stanojević \\ Faculty of Organizational Sciences, Belgrade, Serbia
}

In the twentieth century electricity was produced and transmitted by and between monopolistic public electric power companies. Over the last twenty years, electricity markets have been deregulated allowing customers to choose from a number of competing suppliers and producers. On one hand electricity market participants try to first satisfy their own country's demand and, on the other hand, to transmit electricity across borders into neighborhood markets. Cross-border transmission is part of a competition where market participants have non-discriminatory access to interconnected transmission lines. This paper examines the problem of day-ahead planning at trading sections of electricity companies. The underlying assumption is that the demand and supply are known in advance. Available transmission capacities are also known as well as additional transmission capacities that can be purchased. The prices and amounts of trading and transmission are subjects of auctions. The problem of day-ahead planning is here disscussed from the perspective of a decision maker of an energy trading company (ETC). Decisions to be made are: where and how much electricity should the ETC buy and sell, and which transmission capacity will be used in order to maximize daily profit. The problem is formulated according to real- life experience of a Serbian ETC which trades in Central and South-East Europe. It is further modeled as a directed multiple-source and multiple-sink network and then represented by linear programming (LP) mathematical model in which the total daily profit is maximized subject to market constraints and flow capacities. The main goal of this model is to provide a useful tool for preparing auction bids. Numerical examples are given in order to illustrate possible applications of the model.

Key words: Energy trading, Day-ahead planning, Network flow, LP model

\section{INTRODUCTION}

Single European electricity market provides seamless competition within the electricity supply chain. Energy trading companies (ETCs) buy transmission capacities from transmission system operators (TSOs) [05]. TSOs consistently release actual maximum amounts of a crossborder transmission capacity to the market. ETCs operate in the middle stage of an energy supply chain [20], and, by buying and selling electricity contracts, they try to manage the risk associated with fluctuating prices. Both traders and end-users are prone to apply different financial instruments such as futures contracts, options, and derivatives to protect themselves against price speculations and fluctuations.
There are few ways of producing electricity: nuclear [04], thermo, hydro, solar, wind [03, 10], as well as several ways of trading electricity but the two most common ones are either by the telephone in bilateral transactions (so called "Over The Counter" or OTC, usually through the intermediation of a broker), or through futures markets such as Nordpool or EEX [02]. Some of the key factors to influence energy prices include geopolitical factors, global economic growth, short term weather condition with possible impact on demand, supply disruptions from maintenance or unexpected outages, fuel price fluctuations, and product swapping in response to relative prices [07]. 
The literature on different aspects of energy trading and transmission is extensive. Kristiansen [11] analyses the auction mechanisms at the crossborder annual, monthly or daily transmission capacity auctions in the area of energy trading between Denmark and Germany. Detailed analysis of the perspective for South-East Europe to become a regional wholesale electricity market or electricity exchange zone is given in [12]. Oggioni and Smeers [17] analyse the impact of emission allowance prices on electricity prices and test two different average cost pricing policies, regional and zonal with different effects on electricity markets of Central and Western Europe. Triki et al. [21] consider multiple interrelated electricity markets, and they propose a multi-stage mixed-integer stochastic model for a capacity allocation strategy in a multi-auction competitive market. Quelhas et al. [19] propose a generalized network flow model of the national integrated energy system which incorporates production, transportation of coal, natural gas, and electricity storage with respect to the entire electric energy sector of the U.S. economy. The authors have formulated a multi period generalized flow problem in which the total cost is minimized subject to energy balance constraints. The problem of energy allocation between spot markets and bilateral contracts is formulated as a general portfolio optimization quadratic programming problem by Liu and Wu [13]. Purchala et al. [18] propose a zonal network model, aggregating individual nodes within each zone into virtual equivalent nodes, and all cross-border lines into equivalent border links. Using flow-based modeling, the feasibility of the least granularity zonal model where the price zones are defined by the political borders is analyzed. Hsieh and Chen [08] consider network systems with multiple-source multiple-sink flow such as electrical and power systems. They examine the problem in which resources are transmitted from resource-supplying nodes to resource-demanding nodes through unreliable flow networks. Nowak et al. [16] analysed the simultaneous optimization of power production and day-ahead power trading and formulated it as a stochastic integer programming model. In this paper we proposed an LP mathematical model of total daily profit maximization subject to arranged demand and supply and additional MW and transmission capacity constraints. [15]

We present the problem by a directed multiplesource and multiple-sink network and model using linear programming. Since the right to buy and sell energy and utilize transmission capacity is acquired in auction, the proposed model can be also used as a tool to help decision makers to create bids for auctions. We illustrate this approach with an example of a Serbian ETC trading.

The paper is structured as follows. Section 2 is dedicated to a description of the main assumptions of the observed problem; Section 3 presents an LP model for day-ahead planning; in Section 4 we report and discuss numerical results to illustrate two different ways of model's application. First, we present the solution of an LP model with fixed parameters, and then we investigate the impact of prices on trading capacities and amounts in order to create bids for auctions. Conclusions along with perspectives regarding further study are given in Section 5 .

\section{PROBLEM DESCRIPTION}

The focus of this paper is on electricity trading from the perspective of an ETC. The main task of a trading section of an ETC is to meet each and every customer requirements regardless of the circumstances. The trading section also enables the ETC to respond to the ever-changing state of the regional transmission grid and production capacities. Besides, this section deals with spot and long term arrangements, creating schedules, cross-border capacity allocations, optimization of the whole portfolio, managing different energy sources, customers in different countries and cross- border energy flows and costs.

The efficiency of a trading section of an ETC can be improved by considering at least two optimization problems: long term and short term (dayahead) planning. Long term planning includes assessment of electricity market e.g. buyers and suppliers interested in cooperation, and transmission capacity to be purchased for the next period. Day-ahead planning refers to finding an optimal plan for selling and buying electricity, which will maximize the daily profit considering the available transmission capacities.

Day-ahead planning starts from an established network of potential buyers and suppliers and purchased transmission capacities based on long term decisions. The example of a simplified electricity network where all buyers and suppliers from one country are represented by one node is shown in Figure 1. This network will be used in the later numerical example. 


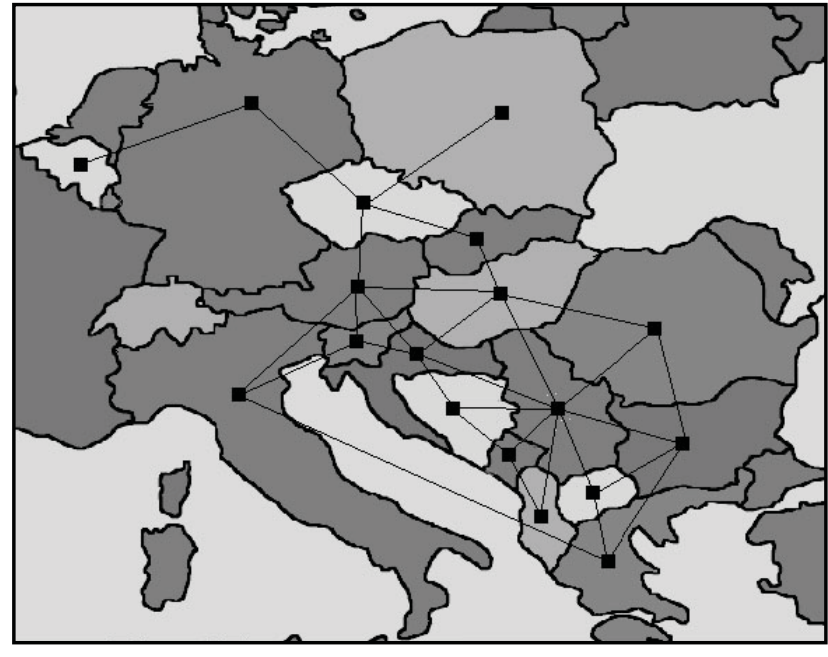

Figure 1: Simplified Central and South-East Europe electricity market

Daily demand and daily supply of each country (node) are known. Data about energy efficiency [09] and loses caused by transmission are already included in quantities of ordered and offered electricity. Electricity trade is carried out during the whole day. At all times decisions are made based on the information collected earlier that day. As the information about demand or supply arrives, new decisions are made. Some electricity trades are already arranged and they must be fulfilled. All the electricity bought during one day has to be sold the same day. Therefore, if there is a surplus or shortage of arranged supply, it will be traded through the futures markets. The futures markets such as EEX and EXAA [23] are the places where an ETC can buy or sell the electricity at less favorable prices. The amounts of surpluses and shortages are diferent for every day.

If an ETC wants to puchase transmission capacities to be at their disposal for a longer period, it is necessary to announce the amount that will be used. This amount is calculated based on assumptions and represents only an approximation of the real-time situation forecasted on the previous day [12]. Only the amounts announced one day before the day-ahead planning are considered available. The transmission capacity which is not announced is subject to a "use it or lose it" principle and will be reoffered at the daily auction [11]. If daily trading exceeds the amount of announced capacity, it is possible to buy additional daily transmission capacities at the auction price.
Each trade is initiated at an auction. Auction items are:

- Amounts of electricity that will be bought or sold, and the prices;

- Transmission capacity prices for the capacities that will be used in addition of those previously purchased and announced

The Serbian ETC in question trades on the electricity market where a uniform price auction type is used. This assumes that each bidder bids a price and amount. The price bid refers to a maximum price they are willing to pay per item, and the amount refers to the number of units they wish to purchase at that price. Typically these bids are sealed - not disclosed to the other buyers until the auction closes. The auctioneer then serves the highest bidder first, giving them the number of units requested, then the second highest bidder and so forth until the supply of the commodity is exhausted. All bidders then pay the unit price equal to the lowest winning bid (the lowest bid out of the buyers who actually received one or more units of the commodity) regardless of their actual bid [22].

In practice, bidders make several bids with different amounts and prices in order to make sure they will buy needed amounts, and at the lowest possible prices.

The goal of this paper is to create a useful tool which will help a decision maker in a trading section of an ETC to simulate market and network situations for different amounts and prices of electricity and transmission capacities. Optimization results should provide a decision maker with the information how to make bids at auctions in order to maximize the ETC total profit.

\section{MODEL FORMULATION}

The described problem can be modeled as a directed multiple-source and multiple-sink network [01].

The notation used to define sets, parameters, and decision variables is as follows.

\section{- Sets}

- N-set of all nodes;

- $S$ - set of all nodes representing sellers, $S \subseteq N$;

- $B$ - set of all nodes representing buyers, $B \subseteq N$;

- $A$ - set of arcs representing transmission capacity between nodes, $A \subset N \times N$; 
- Parameters

- $s u_{j}$ - upper bound of electricity that can be bought from supplier $j, j \in S$;

- $s l_{\text {- - lower bound (arranged buying) }}$ of electricity that can be bought from supplier $j, j \in S$;

- $b u_{i}$ - upper bound of electricity that can be sold to buyer $i, i \in \mathrm{B}$;

- $b l_{i}$ - lower bound (arranged sale) of electricity that can be sold to buyer $i, i \in \mathrm{B}$;

$\circ \mathrm{fi}_{j}$ - announced daily transmission capacity of $\operatorname{arc}(i, j) \in \mathrm{A}$;

$\circ h u_{i j}$ - maximal additional daily transmission capacity which is possible to be bought on $\operatorname{arc}(i, j) \in \mathrm{A}$;

- $c_{j}$ - purchasing price for supplier $j, j \in S$;

○ $d_{i}$-selling price for buyer $i, i \in \mathrm{B}$;
- $a_{i j}$ - price for additional transmission capacities on arc $(i, j) \in \mathrm{A}$;

- $t_{i j}$-taxes for additional transmission capacities on arc $(i, j) \in \mathrm{A}$.

- Variables:

- $x_{j}$ - amount of electricity that should be bought from supplier $j \in S$;

- $y_{i}$-amount of electricity that should be sold to buyer $i \in \mathrm{B}$;

- $h_{i j}$ - amount of additional transmission capacities on arc $(i, j) \in \mathrm{A}$.

All electricity amounts and transmission capacities are expressed in MWh. Unit for all prices and taxes is Euro per MWh.

Using given notation the LP mathematical model for day-ahead planning can be stated.

(MMDAP)

$$
\max Z(x, y, h)=\sum_{i \in B} d_{i} y_{i}-\sum_{j \in S} c_{j} x_{j}-\sum_{(i, j) \in A}\left(t_{i j}+a_{i j}\right) h_{i j}
$$

s.t.

$$
\begin{aligned}
& \sum_{j \in S} x_{j}-\sum_{i \in B} y_{i}=0 \\
& \sum_{(i, j) \in A}\left(f_{i j}+h_{i j}\right)-\sum_{(j, i) \in A}\left(f_{j i}+h_{j i}\right)= \begin{cases}0 & j \in N \backslash(S \cup B) \\
-x_{j} & j \in S \backslash B \\
y_{j} & j \in B \backslash S \\
y_{j}-x_{j} & j \in B \cap S\end{cases} \\
& s l_{j} \leq x_{j} \leq s u_{j}, j \in S \\
& b l_{i} \leq y_{i} \leq b u_{i}, i \in B \\
& 0 \leq h_{i j} \leq h u_{i j},(i, j) \in A
\end{aligned}
$$

Objective function (1) represents the difference between total income and costs of buying electricity and additional transmission capacities. Constraint (2) provides that quantities of electricity that is bought and sold in one day are equal. Since all nodes are transition nodes, a flow conservation constraint (3) must hold. This constraint has four different interpretations depending on a node type. $N \backslash(S \cup B)$ is a set of nodes without demand and supply. For each node from $N \backslash(S \cup B)$ constraints (3) ensure that the amount of electricity entering the node must be equal to the amount of electricity leaving the node. $S \backslash B$ is a set of source nodes in which the amount of electricity entering a node and electricity bought in this node must be equal to the amount of electricity leaving the node while $B \backslash S$ is a set of sink nodes in which the amount of electricity entering a node must equal the amount of electricity leaving the node and electricity sold in this node. $B \cap S$ is a set of source-sink nodes. For each node from $B \cap S$ constraints (3) ensure that the amount of electricity entering the node and electricity bought in this node must equal the amount of electricity leaving that node and electricity sold in that node. Optimal amounts of electricity that should be bought and sold lie between their upper and lower boundaries given by constraints (4) and (5). Constraint (6) refers to the maximal additional daily transmission capacity which can be bought on an arc.

\section{NUMERICAL EXAMPLES}

In order to assess the proposed model we consider two different ways of its application. The first one consists of obtaining an optimal dayahead plan where all parameters have fixed val- 
ues. The second application is based on a more realistic situation where some parameters may vary within certain boundaries. Such approach can help the ETC decision maker to create bids for an auction. Both applications are shown on a CSEE network consisting of 18 nodes and 62 arcs (Figure 2).

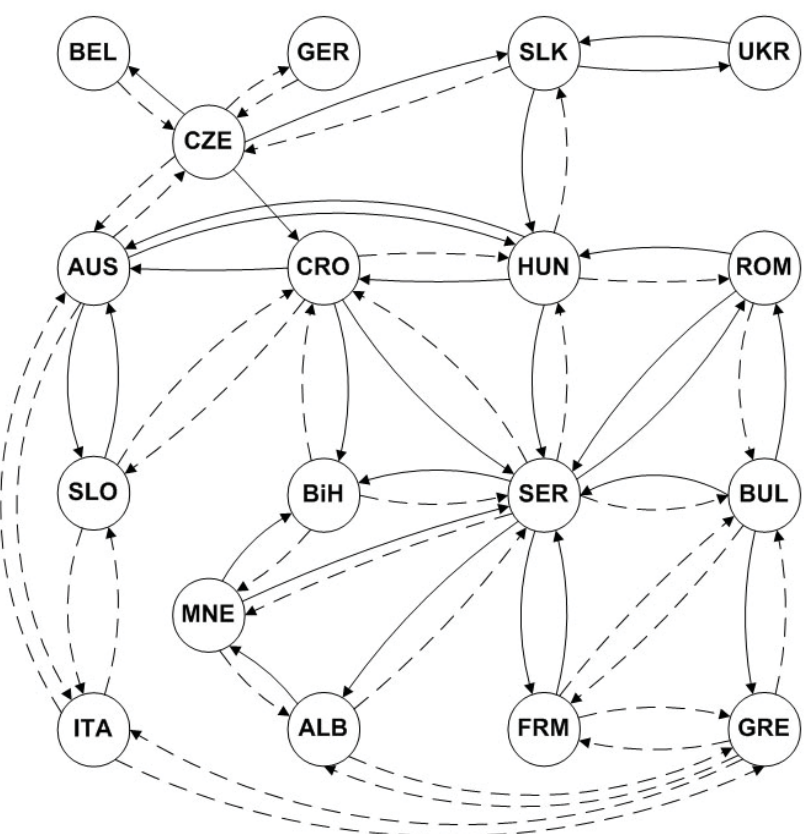

Figure 2: Graph representation of CSEE electricity market
Each country is presented by a node which is characterized by its lower and upper bounds of electricity that can be bought and/or sold in/from that country as well as purchasing and selling prices. All arcs (in Figure 2, both, solid and dashed lines) represent cross-border connections where it is possible to buy additional transmission capacity. Arcs represented by solid lines indicate the existence of announced transmission capacities purchased earlier, while arcs represented by dashed lines represent the unannounced transmission capacities which can be purchased on the daily base. Amounts of announced and maximal additional daily transmission capacities (Table 1) as well as prices and taxes of each arc are also given.

Due to confidentiality issues, in this paper we present a slightly modified data which are within the boundaries of common real-life situations.

The model has been implemented and solved using GNU Linear Programming Kit software intended for solving linear programming (LP), mixed integer programming (MIP), and other related problems [06]. The optimal solution for one scenario is given in Table 2. Marks "/" mean that there were no suppliers or buyers in the corresponding country.

Table 1: Upper bounds for additional transmission capacities

\begin{tabular}{|c|c|c|c|c|c|c|c|c|c|c|c|c|c|c|c|c|c|c|c|}
\hline & BEL & GER & AUS & SLO & ITA & GRE & CZE & HUN & CRO & $\mathrm{BiH}$ & MNE & POL & SLK & SER & ALB & FRM & UKR & ROM & BUL \\
\hline BEL & & & & & & & 200 & & & & & & & & & & & & \\
\hline GER & & & & & & & 500 & & & & & & & & & & & & \\
\hline AUS & & & & 360 & 280 & & 150 & 430 & & & & & & & & & & & \\
\hline SLO & & & 40 & & 100 & & & & 200 & & & & & & & & & & \\
\hline ITA & & & 250 & 150 & & 50 & & & & & & & & & & & & & \\
\hline GRE & & & & & 300 & & & & & & & & & & 280 & 610 & & & 410 \\
\hline CZE & 180 & 50 & 240 & & & & & & & & & & 200 & & & & & & \\
\hline HUN & & & 320 & & & & & & 110 & & & & 500 & 140 & & & & 340 & \\
\hline CRO & & & & 300 & & & & 100 & & 200 & & & & 350 & & & & & \\
\hline $\mathrm{BiH}$ & & & & & & & & & 59 & & 210 & & & 300 & & & & & \\
\hline MNE & & & & & & & & & & 320 & & & & 50 & 120 & & & & \\
\hline \multicolumn{20}{|l|}{ POL } \\
\hline SLK & & & & & & & 420 & 250 & & & & & & & & & 85 & & \\
\hline SER & & & & & & & & 500 & 300 & 200 & 200 & & & & 200 & 400 & & 100 & 200 \\
\hline ALB & & & & & & 85 & & & & & 300 & & & 200 & & & & & \\
\hline FRM & & & & & & 250 & & & & & & & & 460 & & & & & 250 \\
\hline UKR & & & & & & & & & & & & & 390 & & & & & & \\
\hline ROM & & & & & & & & 230 & & & & & & 170 & & & & & 155 \\
\hline BUL & & & & & & 455 & & & & & & & & 49 & & 145 & & 450 & \\
\hline
\end{tabular}


Table 2: Optimal solution

\begin{tabular}{cccc|ccc}
\hline \hline & \multicolumn{3}{c|}{ Buying in MWh } & \multicolumn{3}{c}{ Selling in MWh } \\
\hline \hline node & min & Optimal & max & min & Optimal & max \\
\hline BEL & 18 & 40 & 40 & 25 & 25 & 67 \\
GER & 2 & 70 & 70 & 0 & 70 & 80 \\
AUS & 1 & 31 & 31 & 0 & 0 & 60 \\
SLO & $/$ & $/$ & $/$ & 5 & 5 & 35 \\
ITA & 0 & 36 & 50 & 31 & 41 & 41 \\
GRE & 0 & 0 & 86 & $/$ & $/$ & $/$ \\
CZE & 0 & 61 & 85 & 0 & 0 & 38 \\
HUN & 0 & 0 & 10 & $/$ & $/$ & $/$ \\
CRO & $/$ & $/$ & $/$ & 22 & 22 & 44 \\
BiH & 36 & 52 & 52 & 42 & 49 & 49 \\
MNE & $/$ & $/$ & $/$ & 5 & 5 & 60 \\
SLK & $/$ & $/$ & $/$ & 12 & 12 & 33 \\
SER & 0 & 46 & 46 & 0 & 80 & 80 \\
ALB & 5 & 10 & 35 & $/$ & $/$ & $/$ \\
FRM & 0 & 40 & 40 & 3 & 3 & 57 \\
ROM & $/$ & $/$ & $/$ & 4 & 70 & 70 \\
BUL & $/$ & $/$ & $/$ & 14 & 14 & 25 \\
UKR & 10 & 10 & 20 & $/$ & $/$ & $/$ \\
\hline \hline
\end{tabular}

In addition to optimal trading amounts, the solution determines additional transmission capacities that should be purchased. In this scenario we obtained: $45 \mathrm{MWh}$ on arc BEL-CZE, $5 \mathrm{MWh}$ on arc SLO-ITA, $41 \mathrm{MWh}$ on arc GRE-BUL, etc. Total daily trade is $396 \mathrm{MWh}$. The total daily income is $34068 €$. The cost for buying electricity is $26803 €$, while the cost for additional transmission capacities is $3078 €$. The total profit based on this optimal solution is $4187 €$. In order to obtain this total profit certain corrections of objective function has to be made:

- Taxes for announced transmission capacities and costs of long term purchased transmission capacities evaluated on a daily basis should be subtracted;

- Unit prices for previously arranged buying and selling (blj and slj) can differ from actual prices. These differences should be taken into account

Nevertheless these corrections do not influence the optimality of the obtained solution. In further analysis we will use term "profit" for the value of goal function, although it is just an approximation.

The possibility of buying and selling electricity on futures markets, as well as the possibility of buying additional transmission capacities, will provide the feasibility of all solutions. Since we enabled surpluses and shortages the model will always provide an optimal solution. Based on experiments done so far we noticed that the solution may not always be unique, but that there might be more than one; which one will be chosen depends entirely on the decision maker.

To demonstrate the second way of using MMDAP we have simulated a situation where a decision maker creates bids at an auction for buying electricity from one supplier. In the presented example we observed a supplier in node CZE which offers the amount of $85 \mathrm{MWh}$.

We analysed the influence of the purchasing price changes on the optimal amount of electricity that should be bought and an optimal solution as a whole. Based on the experience we have supposed that the electricity price for the supplier in node CZE can vary from 75 to $93 € / M W h$. A series of optimizations was made for all integer values of prices in the given interval. Table 3 shows the optimal amounts of electricity that should be bought and the corresponding profits for some characteristic prices of electricity, assuming that all other parameters remain the same. 
Table 3: The impact of prices on optimal amount and profit

\begin{tabular}{ccc}
\hline \hline Price & $\begin{array}{c}\text { Optimal } \\
\text { amounts }\end{array}$ & Profit \\
\hline 75 & 85 & 4442 \\
$\vdots$ & $\vdots$ & $\vdots$ \\
77 & 85 & 4272 \\
78 & 61 & 4187 \\
79 & 15 & 4126 \\
$\vdots$ & $\vdots$ & $\vdots$ \\
91 & 15 & 3946 \\
92 & 0 & 3931 \\
93 & 0 & 3931 \\
\hline \hline
\end{tabular}

The decrease of optimal amount of electricity and profit was expected because the purchasing price increased, but all the solutions were optimal if the corresponding price became the lowest winning bid. In other words, for different prices established by auction competition, different amounts of electricity that should be bought (and corresponding profits) are optimal.

Table 4: List of bids derived from optimal solutions

\begin{tabular}{ccc||cc}
\hline Bids & $\begin{array}{c}\text { Amounts } \\
\text { of el. }\end{array}$ & Price & $\begin{array}{c}\text { Accumulated } \\
\text { amount }\end{array}$ & $\begin{array}{c}\text { Guaranteed } \\
\text { profit }\end{array}$ \\
\hline \hline B1 & 15 & $79-91$ & 15 & $4126-3946$ \\
B2 & 46 & 78 & 61 & 4187 \\
B3 & 24 & $75-77$ & 85 & $4442-4272$ \\
\hline
\end{tabular}

On the basis of presented optimal solutions we can suggest the ETC decision maker to make bids shown in the first three columns in Table 4. Depending on the price equal to the lowest winning bid (which will not be known till the end of the auction), the ETC will buy 0, 15, 61 or 85 MWh from node CZE. For prices that are presented as intervals in Table 3, the ETC decision maker can give any price from that interval for which they estimate that it can win. In any case the corresponding amount will be optimal. The profits given in the right column represent the optimal profit if the corresponding bid becomes the lowest winning bid. If any lower bid wins, the profit becomes larger.

\section{CONCLUSIONS}

This paper considers the optimization problems which appear in a trading section of energy trading companies, and one of them, day-ahead energy planning, was formulated as a linear programming problem. Day-ahead energy planning implies finding the optimal amounts of electricity that should be bought from each supplier and sold to each buyer and the optimal routes which can satisfy the daily demands using the purchased and additional energy transmission capacities.

We have formulated LP mathematical model in order to optimize day-ahead energy plan. In adition, the proposed model can be used by an ETC decision maker as a tool for determining optimal bids in auctions for buying or selling electricity as well as for trading transmission capacities.

Two hypothetical numerical examples that demonstrate the use of the model were presented in this paper. Since the developed model is linear, it can be used to solve real-life problems of large dimensions.

We suggest that trading through futures markets be taken into consideration as a topic of further research. Another interesting and useful topic for future study may be the modeling of a long-term planning strategy of energy trading companies.

\section{ACKNOWLEDGMENTS}

This research was partially supported by the Ministry of Education and Science, Republic of Serbia, Projects numbers TR32013 and TR35045.

\section{REFERENCES}

1) Bazaraa, M. S., Jarvis, J. J., Sherali, H. D., (2010) Linear Programming and Network Flows, 4th ed, John Wiley \& Sons, New Jersey

2) Daskalakis, G, Markellos, R. N., (2009) Are electricity risk premia affected by emission allowance prices? Evidence from the EEX, Nord Pool and Powernext. Energy Policy, 37(7), 2594-2604.

3) Fric, N., Gligić, B., Dobrić, J., Marković, Z., (2012) Wind towers - design of friction connections for asembling sections of tubular steel towers, Journal of Applied Engineering Science, (10)1, 49-52

4) Greenberg, M., (2009) Energy sources, public policy, and public preferences: Analysis of 
US national and site-specific data, Energy Policy, 37(8), 3242-3249

5) http://www.efet.org/Position_Papers/Electricity_Market,_Position_Papers,_European_Level_5492.aspx?urllD2r=72. Accessed 15 December 2012

6) http://www.gnu.org/s/glpk/ . Accessed 17 January 2013

7) http://www.harcourt.ch/cms/hauptseite/zeigeBereich/11/gibDatei/1088/26-energypowertrading.pdf. Accessed 14 December 2012

8) Hsieh, C. C, Chen, Y. T., (2005) Resource allocation decisions under various demands and cost requirements in an unreliable flow network, Computers and Operations Research, 32(11), 2771-2784

9) Jovanović, B., Božanić, V., Jovanović, B. (2013) Education in the field of energy efficiency in serbia-survey results and analysis", Journal of Applied Engineering Science, (11) 1, 15-22

10) Komarov, D., Stupar, S., Posteljnik, Z., (2011) Review of the current wind energy technologies and global market, Journal of Applied Engineering Science 9(4), 437-448

11) Kristiansen, T., (2007a) An assessment of the Danish-German cross-border auctions, Energy Policy, 35(6), 3369-3382

12) Kristiansen, T., (2007b) Cross-border transmission capacity allocation mechanisms in South East Europe, Energ Policy, 35(9), 4611-4622

13) Liu, M., Wu, F. F., (2007) Portfolio optimization in electricity markets, Electric Power Systems Research, 77(8), 1000-1009

14) Marchenko, O., (2007) Mathematical modelling of electricity market with renewable energy sources, Renewable Energy, 32(6), 976-990

15) Marinović, M., Stanojević, M., MakajićNikolić, D., (2011) LP Model for Day-ahead Planning in Energy Trading. 11th International Symposium on Operations Research - SOR'11, 75-80
16) Nowak, M. P., Schultz, R. D., Westphalenm M. A., (2005) Stochastic Integer Programming Model for Incorporating Day-Ahead Trading of Electricity into Hydro-Thermal Unit Commitment, Optimization and Engineering, 6(2), 163-176

17) Oggioni, G., Smeers, Y., (2009) Evaluating the impact of average cost based contracts on the industrial sector in the European emission trading scheme, Central European Journal of Operations Research, 17(2), 181-217

18) Purchala, K., Haesen, E., Meeus, L., Belmans, R., (2005) Zonal network model of European interconnected electricity network, CIGRE/IEEE PES, International Symposium New Orleans, 362 - 369

19) Quelhas, A., Gil, E., McCalley, J. D., Ryan, S. M., (2007) A Multiperiod Generalized Network Flow Model of the U.S. Integrated Energy System: Part I-Model Description, Power Systems, IEEE Transactions, 22(2), $829-836$

20) Thery, R., Zarate, P., (2009) Energy planning: a multi-level and multicriteria decision making structure proposal, Central European Journal of Operations Research, 17(3), 265-274

21) Triki, C., Beraldi, P., Gross, G., (2005) Optimal capacity allocation in multi-auction electricity markets under uncertainty, Computers and Operations Research, 32(2), 201-217

22) Vijay, K., (2002) Auction theory, Academic Press, San Diego

23) Zachmann, G., (2008) Electricity wholesale market prices in Europe: Convergence?, Energy Economics, 30(4), 1659-1671

Paper sent to revision: 10.10.2013.

Paper ready for publication: 11.12.2013. 